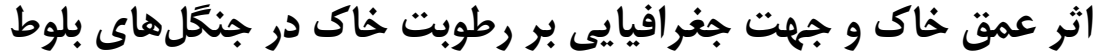 دجار خشكيد خَى (تحقيق موردى: جنغَل مله سياه، استان ايلام)
}

اياد اعظمى '، احمد حسينى 'و جعفر حسينز ادهّ

ا - مربى تحقيق، بخش تحقيقات جنكل و مرتع، مركز تحقيقات و آموزش كشاورزى و منابع طبيعى استان ايلام، سازمان تحقيقات، آموزش و ترويج كشاورزى، ايلام، ايران

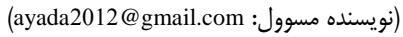

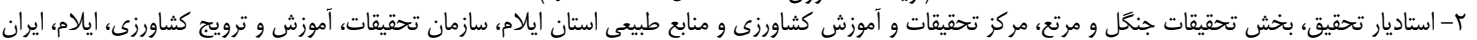

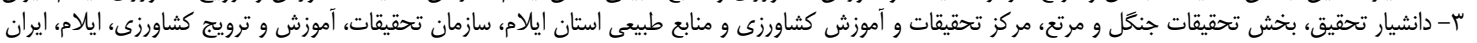

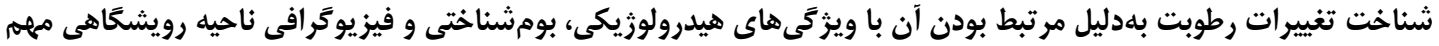
קكيده

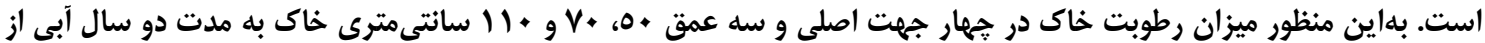

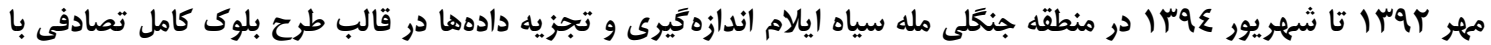

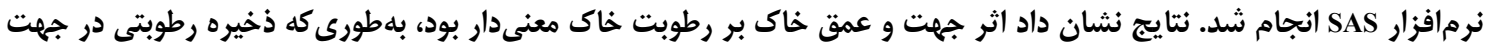

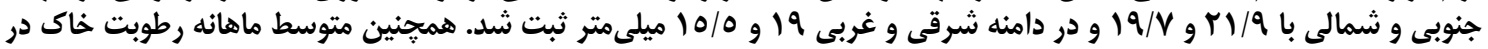

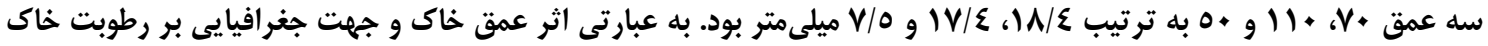

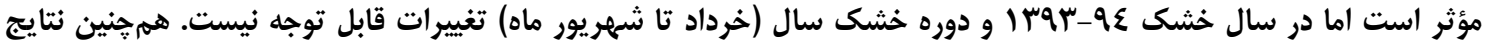

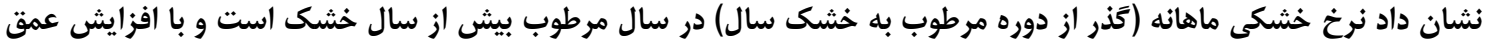

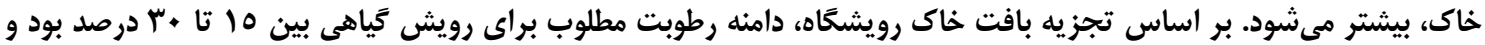

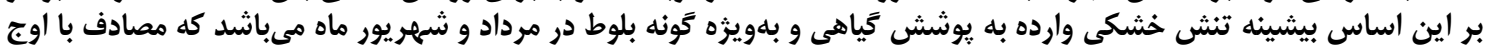

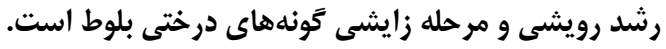

وازههاى كليدى: بلوط، جهت جغرافيايى، عمق خاك، خشكيدتى، رطوبت خاك

جنوبى و يالها است. اكرخه ميزان محدوديت در رويشگاه

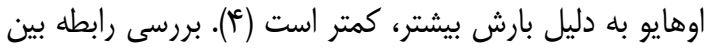

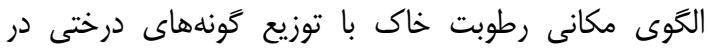

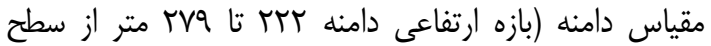

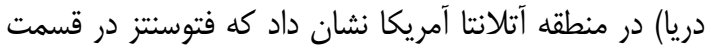

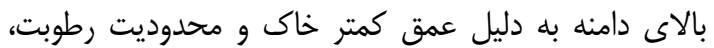

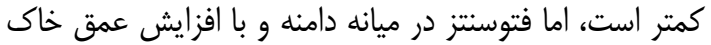

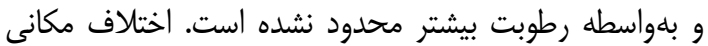

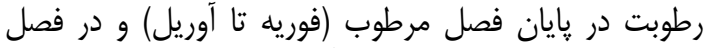

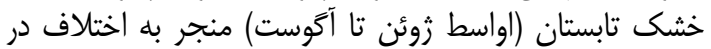

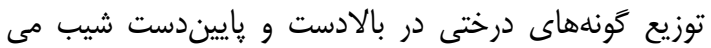

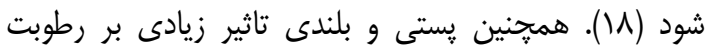

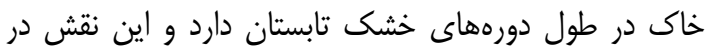

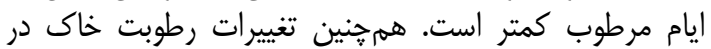

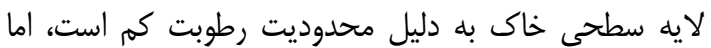

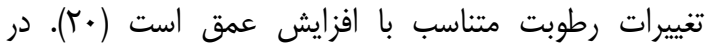

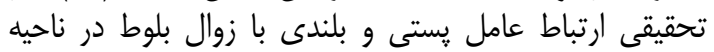

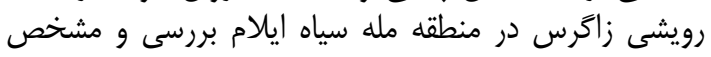

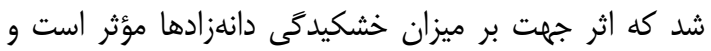

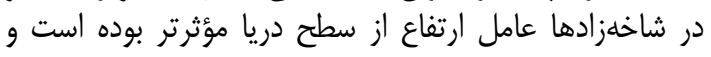

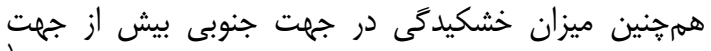

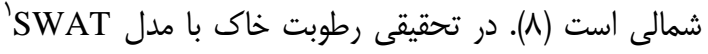

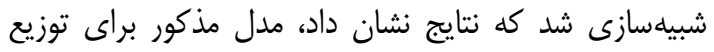

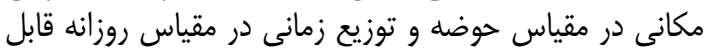

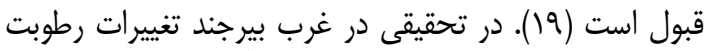

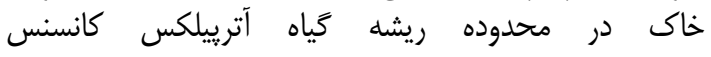

مقدمله محتوى خاك يكى از فاكتورهاى مؤثر در رشد كَياه

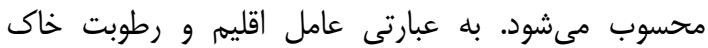

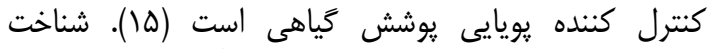
تغييرات رطوبت بهدليل مرتبط بودن بوني آن بات خصوصيات

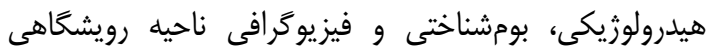

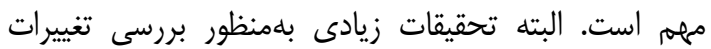

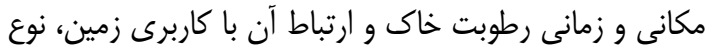

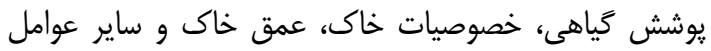

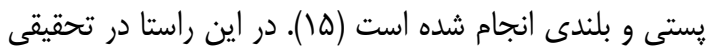

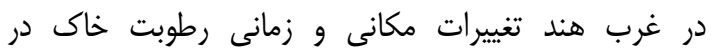

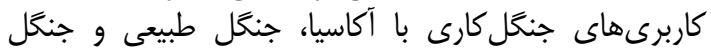

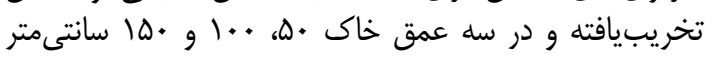

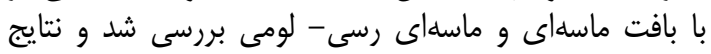

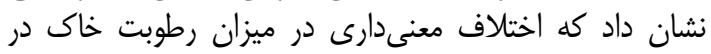

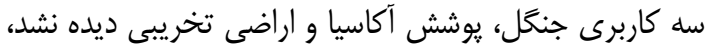

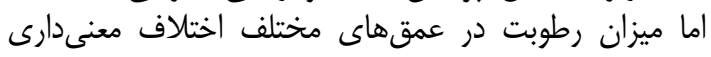
داشتند.

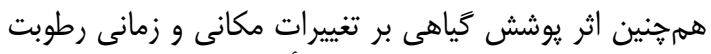

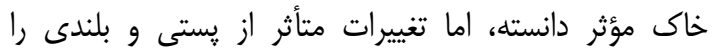

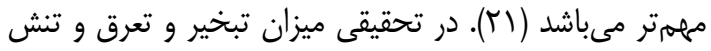

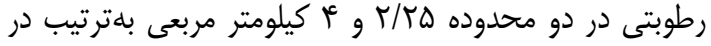

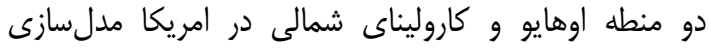

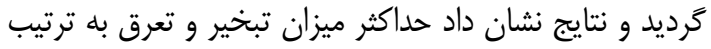

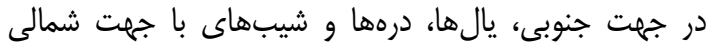
مىباشد و بيشترين محدوديت رطوال رطوبت خاك ران را در شيب شالى 
دليل استفاده اين شاخصها را ماهيت ديناميكى و رابطه مستقيم اين شاخصها با ساير شرايط اقليمى وانائ و خاك دانستهاند (Tه). با توجه به اهميت موضوع، در تحقيق ييش رو رو سعى إنى

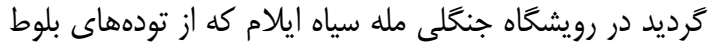

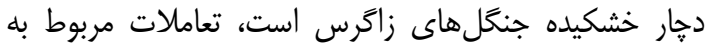

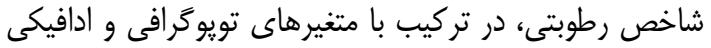

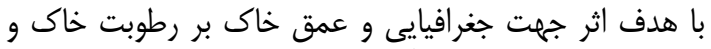
تعيين ماههاى دهار تنش جنى آبى بررسى شود.

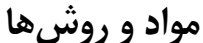 منطقه مورد مطالعه}

منطقه مورد مطالعه در رويشكاه مله سياه از توابع بخش مور موار

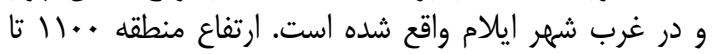

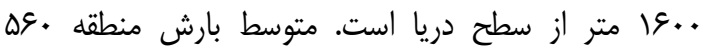

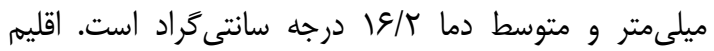

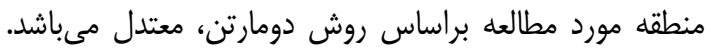
منطقه اجراى طرح بر روى سازند زمينشناسى داسى ايلام واقع شده

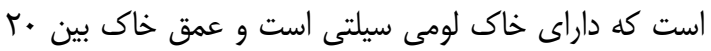

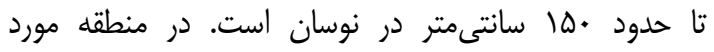

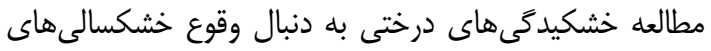

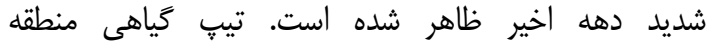

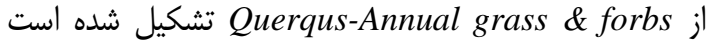
(سا). مختصات جغرافيايى منطقه و موقعيت نقاط اندازهگيرى رطوبت در شكل ا نشان داده شده است.
براسى و نتايج نشان داد كه رطوبت (Atriplex Canescens)

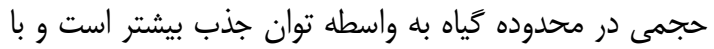

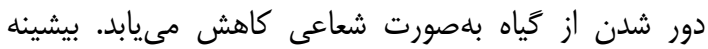

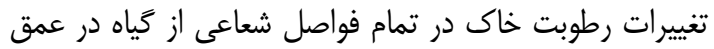

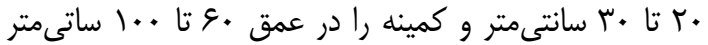

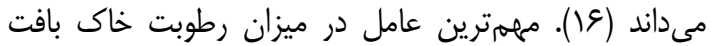

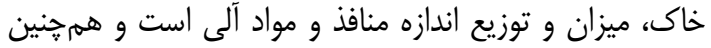

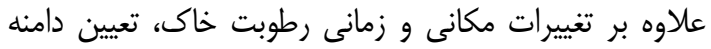

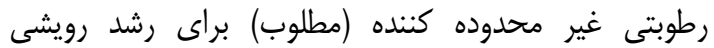

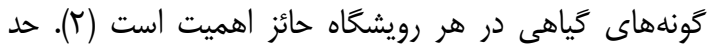

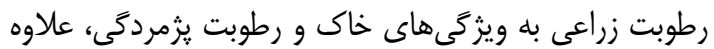

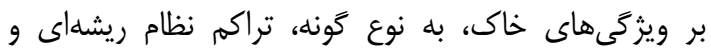

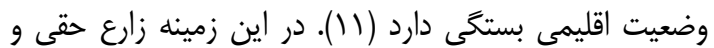

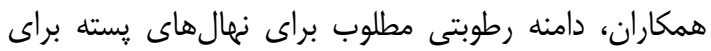

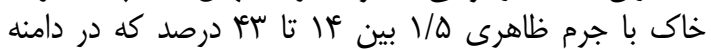

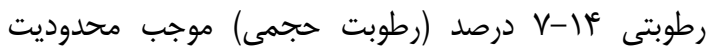

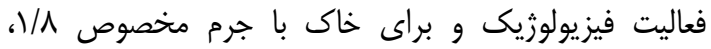

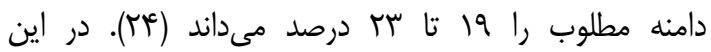

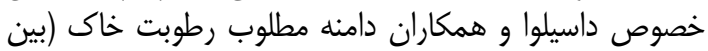

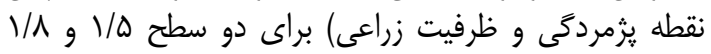

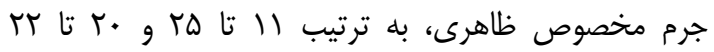

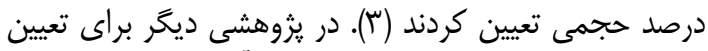

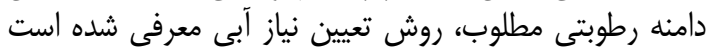

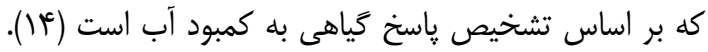

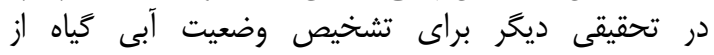

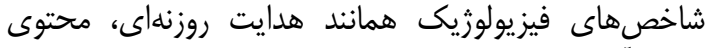
نسبى آب بركى، ميزان يرولين و سطح برى استفاده نمودند و

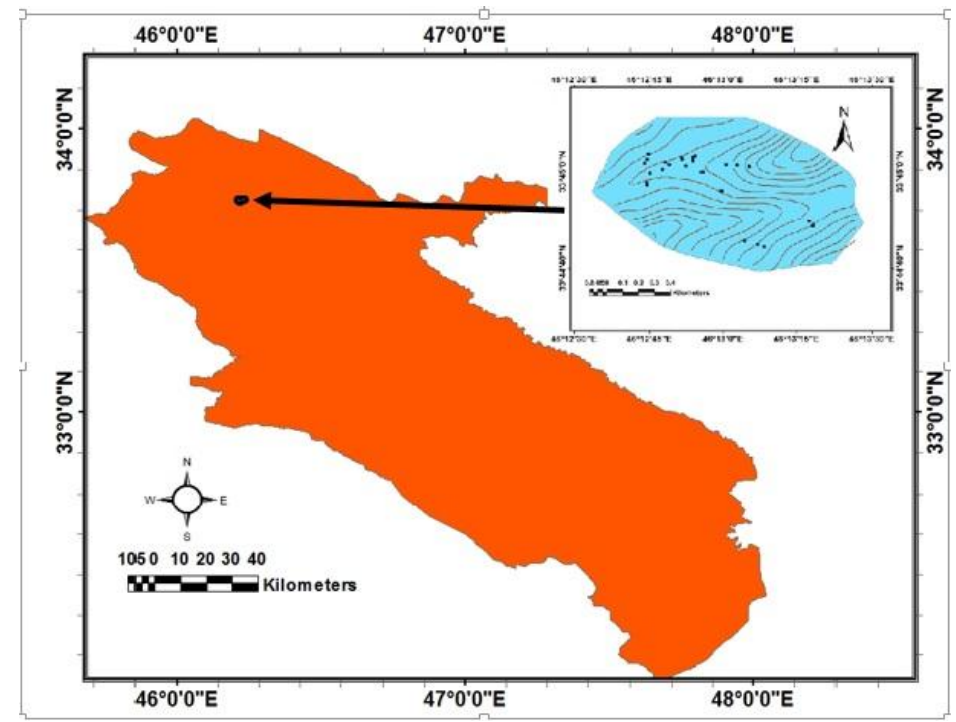

شكل 1- موقعيت منطقه مورد مطالعه بر روى نقشه استان ايلام

Figure 1. Location of the studied area on the map of Ilam province 


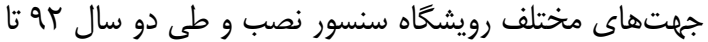

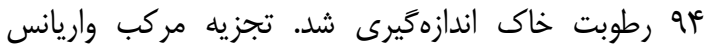

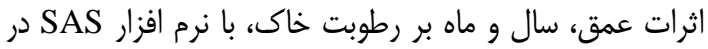

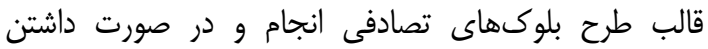
اختلاف معنىدار از آزمون دانكن جهادت برام درسى مقائه ميانخين ها استفاده شد. بـ- تعيين دامنه رطوبتى مطلوب خاك براى رشد روينى رويشى يوشش كياهى براى اين منظور در محل نصب سنسور رطوبتسنج، اقدام

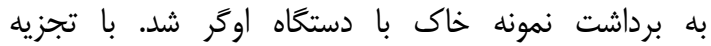

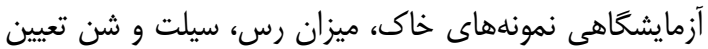

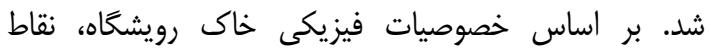

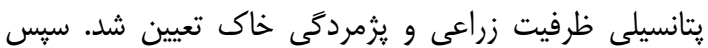

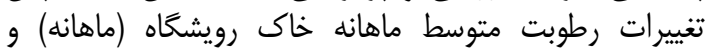

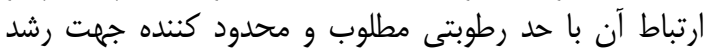

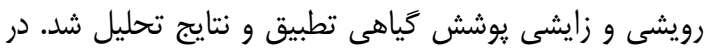

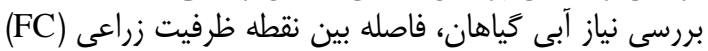

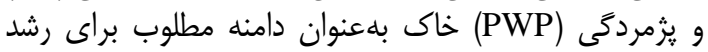

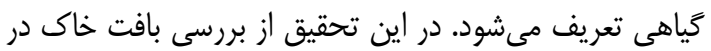

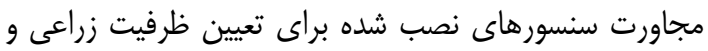

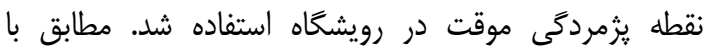

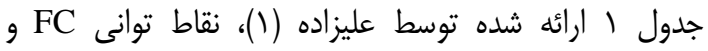
نمونهاى خاك تعيين شد.

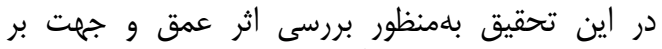

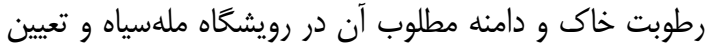
دوره زمانى تنش خشكى وارئ دارده به يوشش دئ دياهى، مراحل اجرا

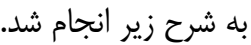

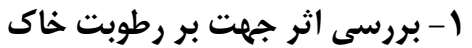

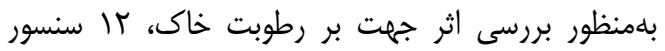

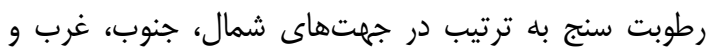

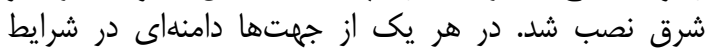

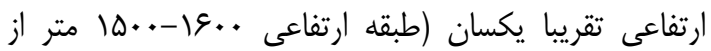

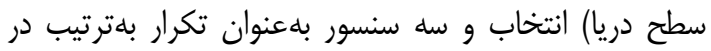

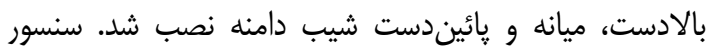

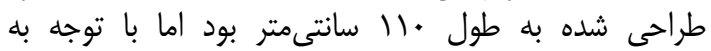

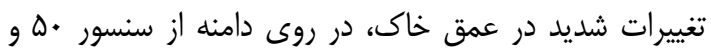
V.

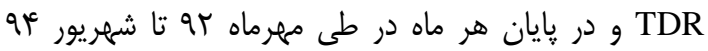

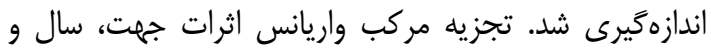

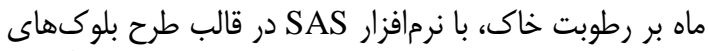

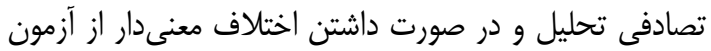
دانكن جهت بررسى مقايسه ميانكَين ها استفاده شد.

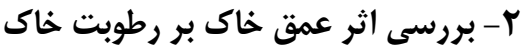

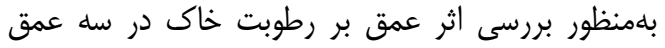

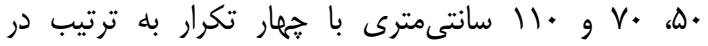

جدول (- مقادير يارامترهاى آب- خاى در بافتهاى مختلف (مأخذ )

Table 8. Water-soil parameters in different tissues (Source: Alizadeh, 2013)

\begin{tabular}{|c|c|c|c|}
\hline ظرفيت دسترسى & نقطه يخمردمى & ظرفيت مزرعه & كلاس بافت \\
\hline$\cdot 1 \cdot 1$ & .1 .4 &.$/ 1 T$ & شنى \\
\hline $.1 \cdot 1$ & .1 .9 &.$/ 1 F$ & لومي شنى \\
\hline זות. & .11 & תז/. & شنى لومى \\
\hline.$/ 1{ }^{4}$ &.$/ 1 T$ & ( & لومى \\
\hline.$/ 10$ & .110 &.$/ \mu$. & سيلت لومى \\
\hline.$/ 1 V$ & .110 & 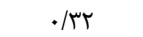 & سيلت \\
\hline .110 & $.1 / 9$ &.$/ M F$ & لومى رسى سيلتى \\
\hline .110 & $\cdot|r|$ & ع צr/. & سيلتى رسى \\
\hline .110 &.$|r|$ & ع ع / . & رس \\
\hline
\end{tabular}

بارانسنج نصب شده در محل اجراى تحقيق، سال سو-rوسا

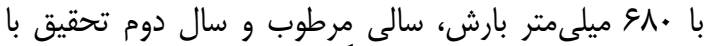

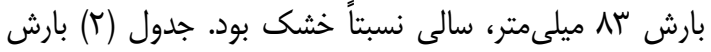

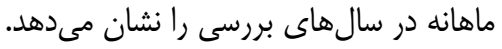

\section{نتايج و بحث \\ وضعيت بارندكى در دوره مورد مطالعه}

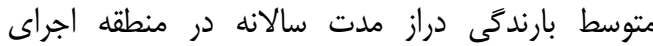

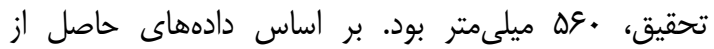

Table 2. Monthly rainfall in survey years to millimeters

جدول r- بارندگى ماهانه در سالهاى بررسى به ميلىمتر

\begin{tabular}{|c|c|c|c|c|c|c|c|c|c|c|c|c|}
\hline شهريور & مرداد & تير & خرداد & ارديبهشت & فروردين & اسفند & بهمن & دى & أذر & آبان & مهر & سال أبى \\
\hline $\begin{array}{ll}- \\
-\end{array}$ & 11 & - & $\cdot / \Gamma^{c}$ & $\mathrm{TV} / \mathrm{V}$ & $r r / K$ & $9 \% / 1$ & $101 / \Gamma$ & $19 / 9$ & $1 . \Gamma / \mu$ & $19 \% / V$ & - & $1 T q T-q T$ \\
\hline $1 / 4$ & $q / \kappa^{k}$ & $\cdot / V$ & - & $1 . / V$ & $r_{N} / 9$ & $V \in / T$ & $r \varepsilon / \varphi$ & $\mu c / \bar{q}$ & $\mu q / r$ & $\Lambda V / r$ & $\Delta \cdot / r$ & $1 \% q \Psi-q F$ \\
\hline
\end{tabular}

آمده است، حاكى از آن است كه اثر جهت، سال و ماه بر مقادير رطوبت خاكى معنى دار بود آن است
اثر جهت بر رطوبت خاك در رويشًَاه مله سياه ايلام

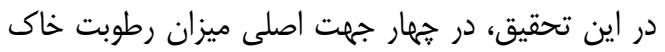

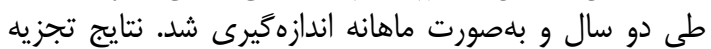

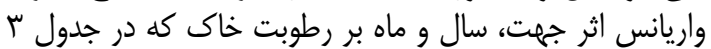


جدول r- تجزيه واريانس اثر جهت، سال و ماه بر رطوبت خاك در رويشگاه مله سياه ايلام

Table 3. Analysis of variance of direction, year and month effects on soil moisture in Melleh Siah Ilam habitat

\begin{tabular}{|c|c|c|c|c|c|}
\hline سطح معنىدارى & أماره فيشر & ميانگين مربعات & مجموع مربعات & درجه أزادى & منبع تغييرات \\
\hline$<\cdot|\cdots \cdot|$ & $N / q^{2}$ & $1 I G N / T V$ & $\Gamma \Delta \cdot \Delta / 11$ & $\mu$ & جهت \\
\hline$<\cdot|\cdots \cdot|$ & $\mu F / l e$ & rar. & far. & 1 & سال \\
\hline$<\cdot|\cdots|$ & $V / \Lambda \Gamma$ & $1 . \Delta Q / T \Delta$ & $\| \& Q \backslash / \Lambda \mid$ & 11 & \\
\hline
\end{tabular}

زمانى رطوبت خاك مؤثر بوده، اما تغييرات ناشى از رستى و

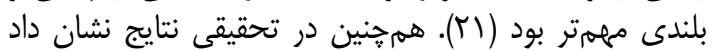

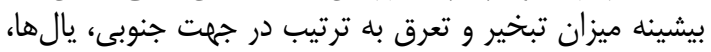

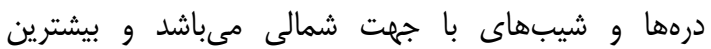

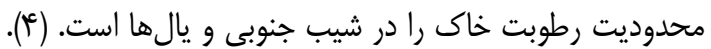

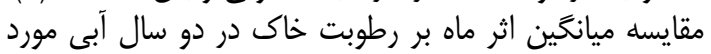

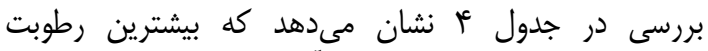

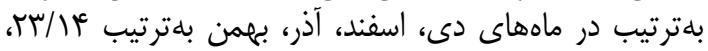
ماهماي خ/TV

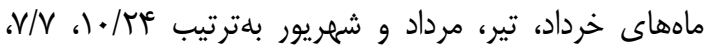

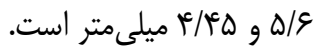

مقايسه ميانگين رطوبت خاك در جهتهاى مختلف نشان

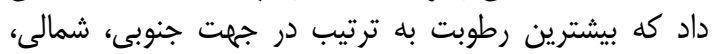

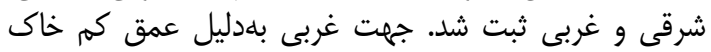

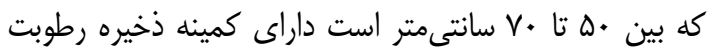

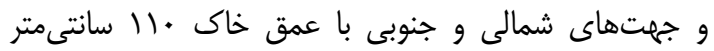

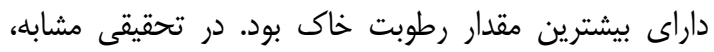

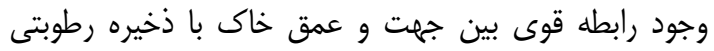

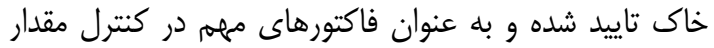

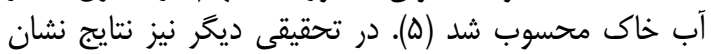

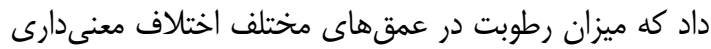

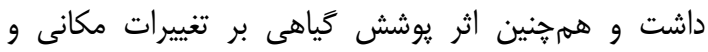

Table 4. Comparison of monthly soil moisture content to millimeters

جدول بأ- مقايسه ميانگين رطوبت خاك ماهانه به ميلىمتر

\begin{tabular}{|c|c|c|c|c|c|c|c|c|c|c|c|c|}
\hline شهريور & مرداد & تير & خرداد & ارديبيهشت & مهر & فروردين & أبان & بهمن & آذر & اسفند & נى & ماه \\
\hline$F / F \Delta^{\mathrm{e}}$ & $\Delta / \gamma^{\mathrm{e}}$ & $\mathrm{V} / \mathrm{v}^{\mathrm{de}}$ & $1 . / \pi f^{\mathrm{cd}}$ & $1 T / T q^{c}$ & $I \Gamma / \Lambda \Gamma^{c}$ & $M / \Delta^{b}$ & $M / A r^{b}$ & $r \cdot / 9 \Delta^{a b}$ & $r y / \wedge^{\mathrm{ab}}$ & $r / / r v^{\mathrm{ab}}$ & $r \mu / l r^{a}$ & يين \\
\hline
\end{tabular}

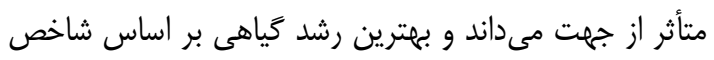

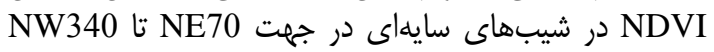

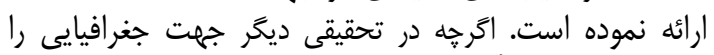

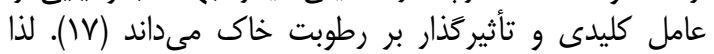

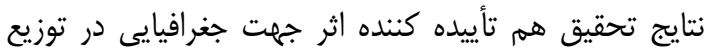

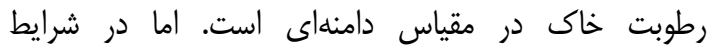

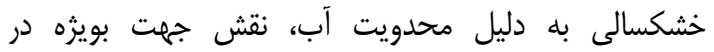

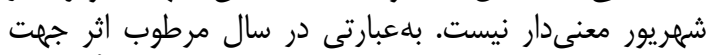

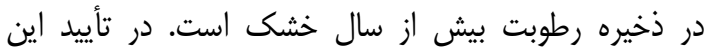

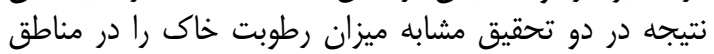

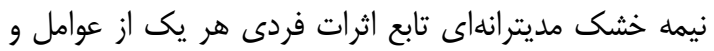

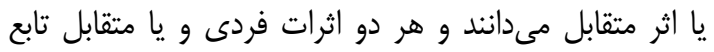

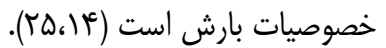
بررسى اثر عمق بر رطوبت خاك است

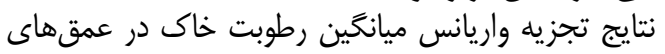

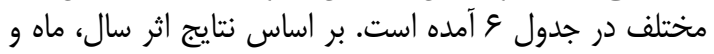
عمق خاى بر رطوبت خاك معنى دار است.

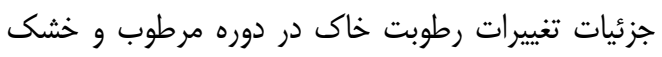

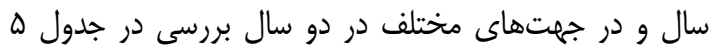

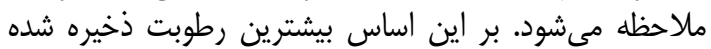

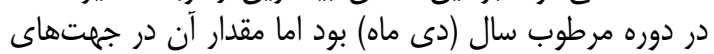

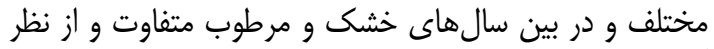

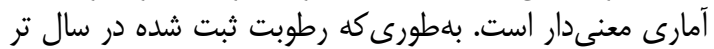

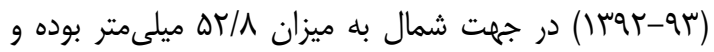

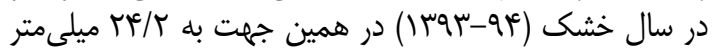
رسيد. همرجنين در خايان دوره خشك خد سال (شهريور ماه) رطوبت خاك به حداقل خود ميرسل درد، كه اين مقدار در در سال

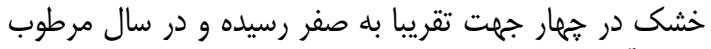

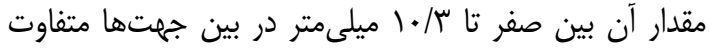

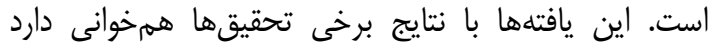
(V.)+6IV)

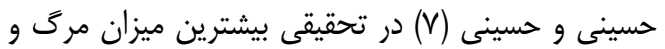

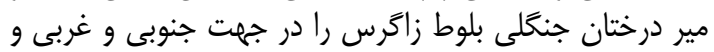

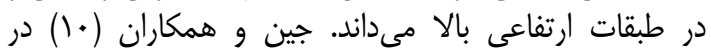

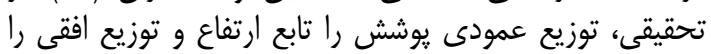

جدول ه- متوسط، كمينه و بيشينه رطوبت سالانه اندازه گيرى شده در جهتهاى جغرافيايى در رويشگاه مله سياه ايلام Table 5. Average, minimum and maximum annual moisture measured in the geographical directions of the location of the Melleh Siah Ilam

\begin{tabular}{|c|c|c|c|c|c|c|}
\hline \multicolumn{3}{|c|}{ سال عq4qو } & \multicolumn{3}{|c|}{ سال سو-9ז9 } & \\
\hline بيشينه & متوسط & كمينه & بيشينه & متوسط & كمينه & \\
\hline$T F / T$ & $1 . / 9$ &.$/ T$ & $\Delta T / \Lambda$ & $r \cdot / q$ & $1 . / \mu$ & شمال \\
\hline rq/द & $14 / V$ & . & $|c| / s$ & $r \mu / q$ & $r / l$ & جنوب \\
\hline $\mid r / s$ & $v$ & . & $r \Delta / r$ & $9 / V$ & . & غرب \\
\hline$r V / r$ & $1 . / 8$ & . & $\Delta \Psi / \mathcal{G}$ & $r M / r$ & $r / T$ & شرق \\
\hline
\end{tabular}


جدول צ- تجزيه واريانس اثر عمق خاى بر رطوبت خاك در رويشگاه مله سياه ايلام Table 6. Analysis of variance effect of soil depth on soil moisture in habitat of Melleh siah Ilam

\begin{tabular}{|c|c|c|c|c|c|}
\hline سطح معنى دارى & أماره فيشر & ميانخين مربعات & مجموع مربعات & درجه آزادى & متغير \\
\hline$<+1+\cdots 1$ & Tr/qV & $F \cdot \mu V / \mu$ & $F \cdot \mu V / r$ & 1 & سال \\
\hline$<+1+\cdots+1$ & $\varepsilon$ & $V m V / \cdot f$ & $\Lambda 1 \cdot V / c$ & 11 & ماه \\
\hline$<\cdot 1 \ldots .1$ & rI/T & rQQT/QR & $\Delta \backslash \Delta V / \Lambda \Delta$ & r & عمق \\
\hline
\end{tabular}

واكنش سريعتر توان ماتريك خاك به رزيم حرارتى و تراكم

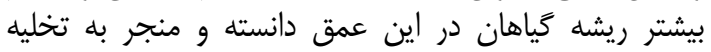

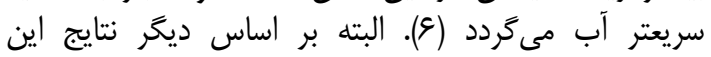

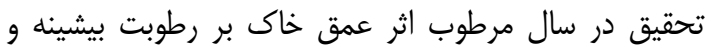

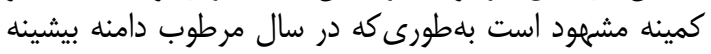

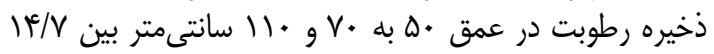

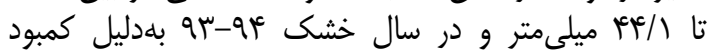

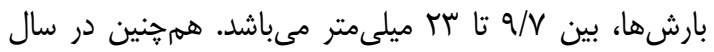

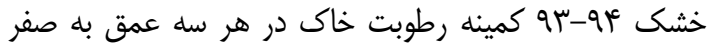

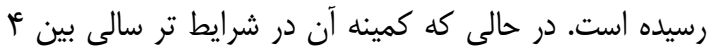

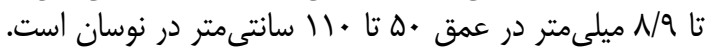

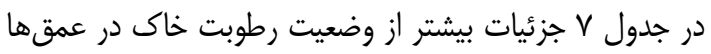
و سالهاى بررسى نشان داده شده است.

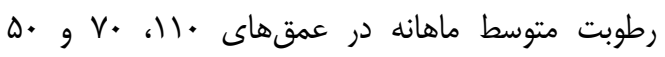

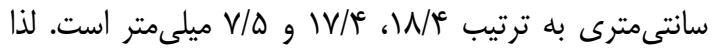

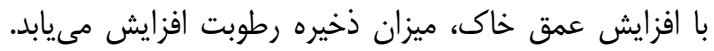

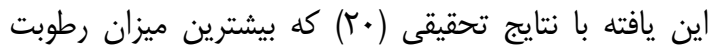

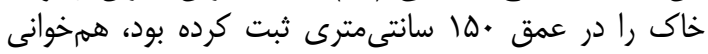

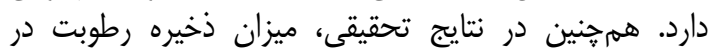

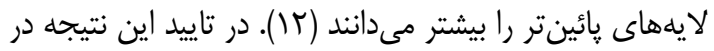

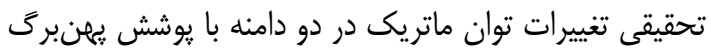

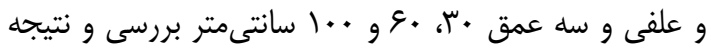

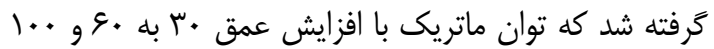

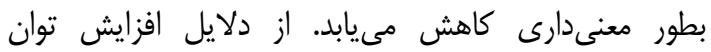

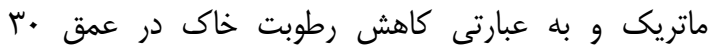
سانتىمترى به نفوذ جريان عمودى آب به عمق راكي دائينتر،

جدول V- دامنه تغييرات رطوبت خاك (ميلىمتر) در عمق هاى مختلف در جنگل بلوط مله سياه ايلام Table 7. Range of soil moisture variations (mm) at different depths in oak forest of Melleh siah Ilam

\begin{tabular}{|c|c|c|c|}
\hline \multicolumn{3}{|c|}{ دامنه تغييرات رطوبت خاك (ميلىمتر) } & عمق \\
\hline متوسط دو سال بررسى & سال & سال rq-qצq & (سانتىمتر) \\
\hline$\cdot / 4-14 / \mathrm{V}$ & $\cdot-9 / 7$ & $r-1 \% / V$ & a. \\
\hline$. F-T N / T$ & $\cdot-\mid \omega / V$ & $Q / V-r N / T$ & v. \\
\hline$\cdot / F-F F / 1$ & שו- & $\mid r-\mu \varphi / 1$ & 11. \\
\hline$\cdot|\Delta-\mu|$ & $\cdot / \Lambda-1 N / \Lambda$ & N/q-rা & متوسط \\
\hline
\end{tabular}

تغييرات رطوبت در لايه سطحى خاك به دليل محدوديت، كم دانست (1) (1). در تأيبد اين نتيجه در تحقيقاتى متعدد اشاره شده است

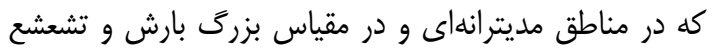

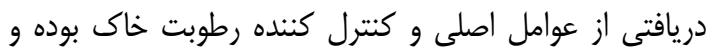

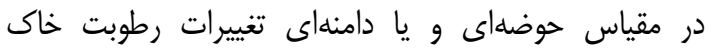

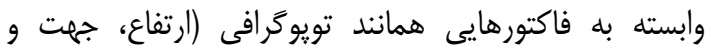

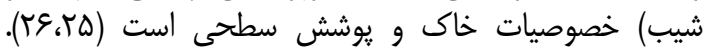

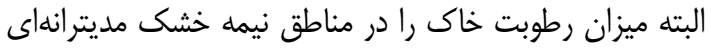

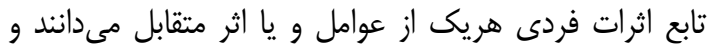

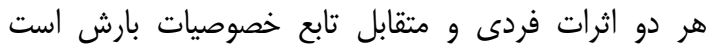

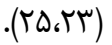

بلهبارتى تغييرات رطوبت در خاك سطحى بيش لايههاى

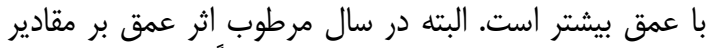

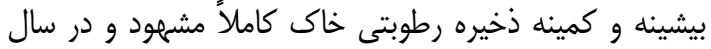

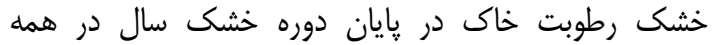

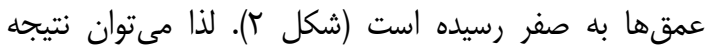

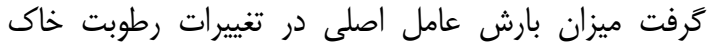

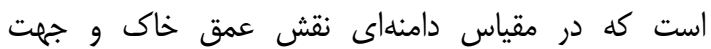

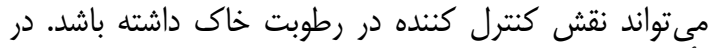

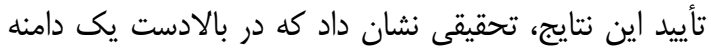

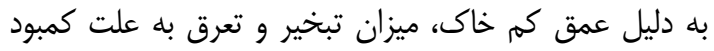

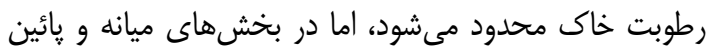

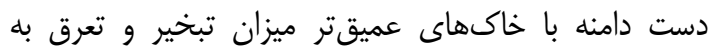

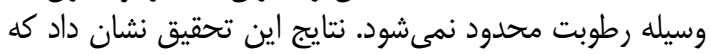




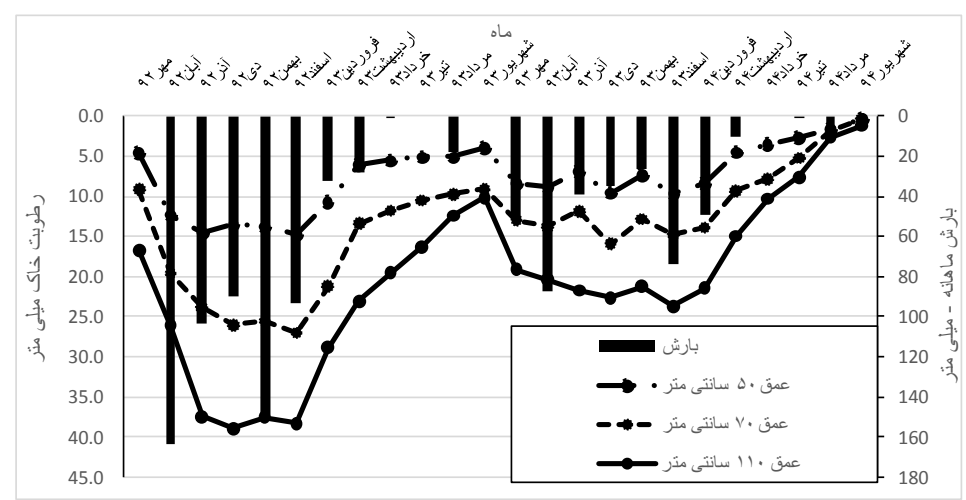

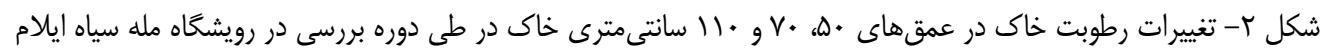

Figure 2. Changes in soil moisture at depths of 50,70 and $110 \mathrm{~cm}$ during the period of review on the Melheh Siah Ilam

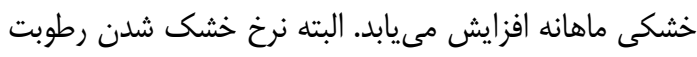

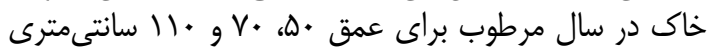

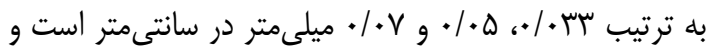

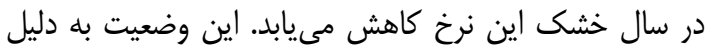

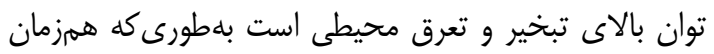

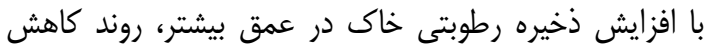
رطوبت خاك هم تسريع مى شوده.

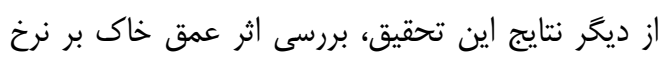

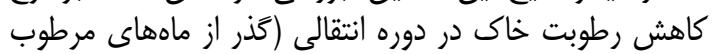

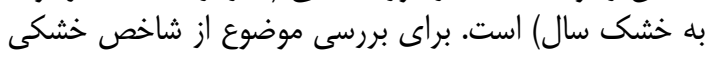

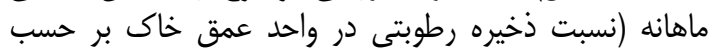

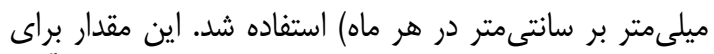

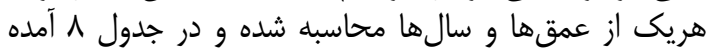

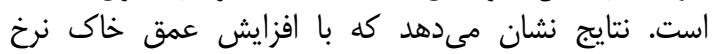

جدول ^- شاخص نسبت خشكى ماهانه رطوبت خاك در عمق خاك در دوره مورد بررسى در رويشآ مله سياه ايلام Table 8. Monthly Drought Index of Soil Moisture in Soil Depth in the Period on the habitat of Melheh Siah Ilam

\begin{tabular}{|c|c|c|c|c|}
\hline 11. & $V \cdot$ & $\Delta \cdot$ & & عمقهاى خاك (سانتىمتر) \\
\hline r & $r \Delta / 1$ & $19 / \pi$ & $14 q r-q 4$ & \multirow{4}{*}{ متوسط رطوبت خاك در مرطوبترين ماه سال (ميلىمتر) } \\
\hline$r r / q$ & $\mid r / 1$ & 1.11 & וrqu-qf & \\
\hline$\cdot / \cdot v$ &.$/ \cdot \Delta$. & سז./. & س & \\
\hline $.1 \cdot+\wedge$ & . & מז./. & $\mid r q u-q f$ & \\
\hline
\end{tabular}

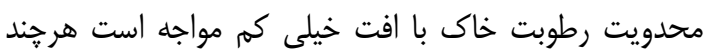
كه مقدار كاهش هم متوبت خاك باس افت با عمق خاك است مواجه
در شكل س روند كاهش رطوبت ماهانه در دوره انتقالى

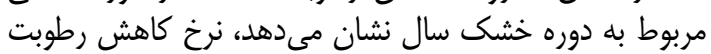

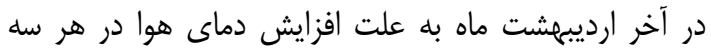

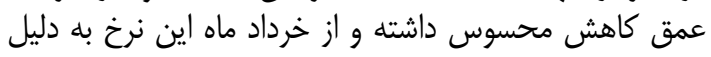

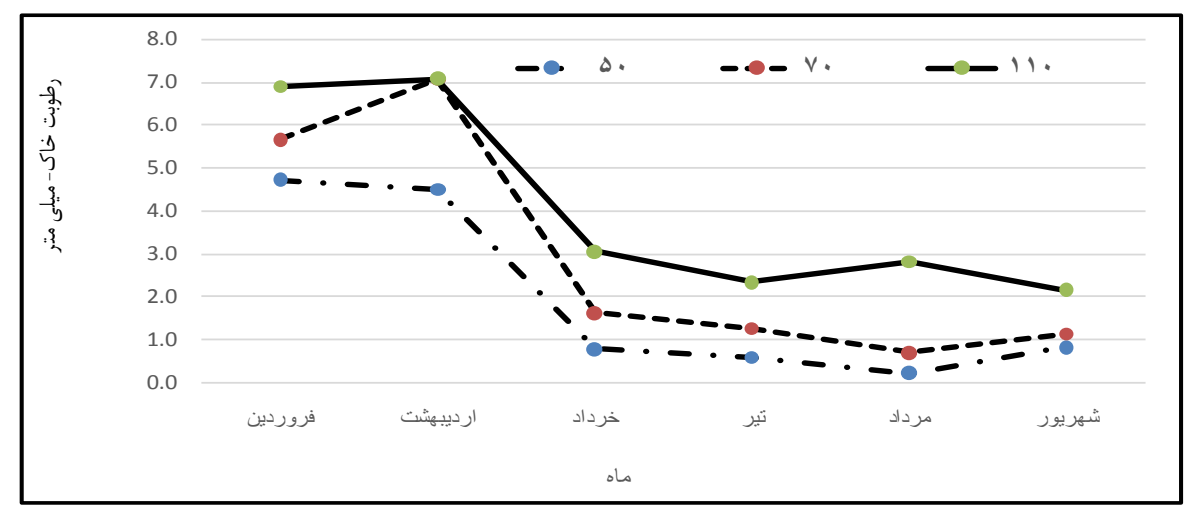

شكل س- نرخ كاهش ماهانه رطوبت خاك مربوط به دوره خشك سال در عمقهاى مورد بررسى در سال سو-بو در رويشگاه مله سياه ايلام

Figure 3. Monthly decreases in soil moisture related to the dry period at the depths studied in the year 2013-2014 on the habitat of Melheh Siah Ilam 
رويشى تياهان

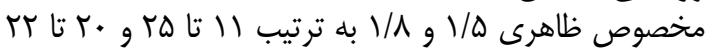

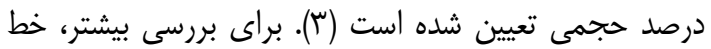

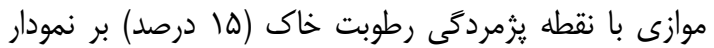

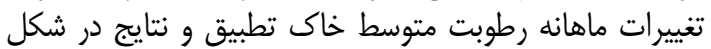

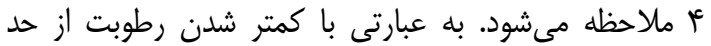

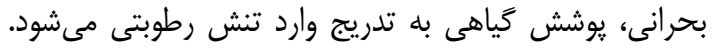

تعيين دامنه رطوبتى خاى محدود كننده براى رشد

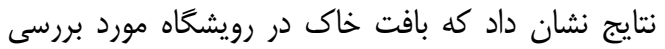

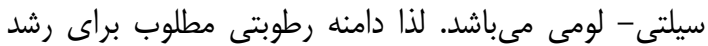

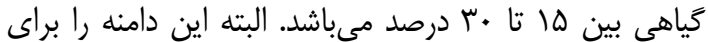

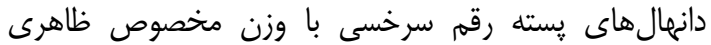

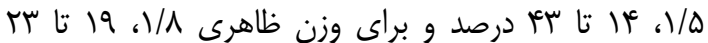

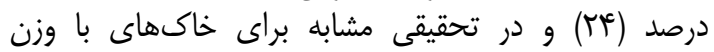

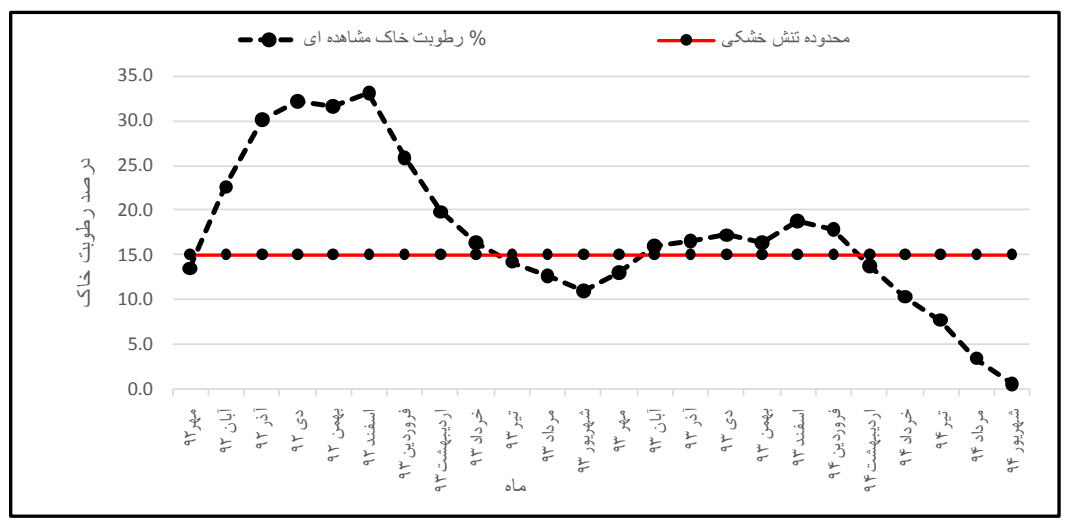

شكل f - تغييرات رطوبت خاك ماهانه و حد بحر انى رطوبت (PWP) در رويشًاه ملهسياه ايلام

Figure 4. Monthly Moisture and Critical Moisture Changes (PWP) in on the habitat of Melheh siah Ilam

دامنه و يوشش سطحى به شكل فردى و يا اثر متقابل آنها در

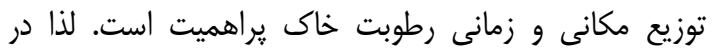

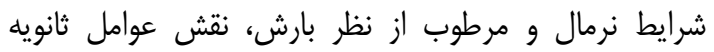

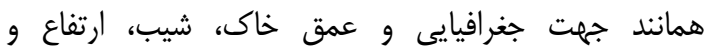

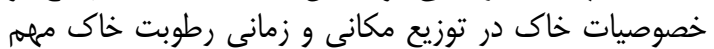

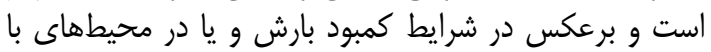

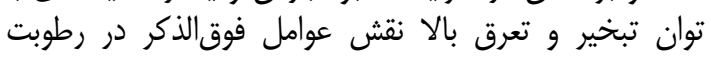

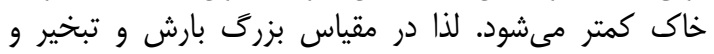
تعرق (تابع تشعشع خورشيدى دريافت شدهاه

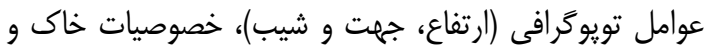
يوشش سطحى نقش ثانويه ايفا مى كنند (Tهاع).

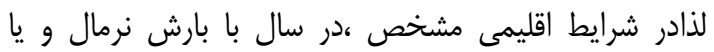

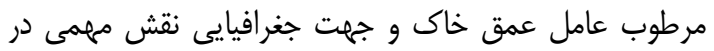

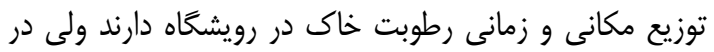

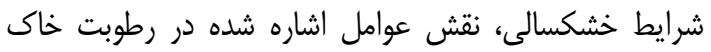

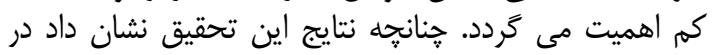

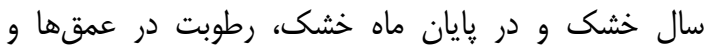
جهتهاى مختلف بله عدد صفرمى رسد.
بر اين اساس ميزان رطوبت خاك در سال مرطوب

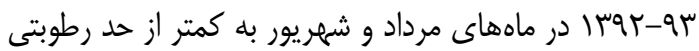

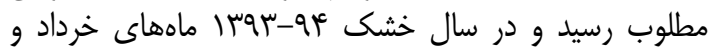

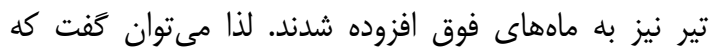

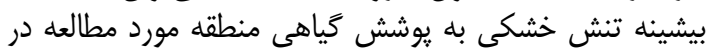

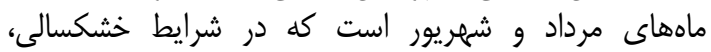

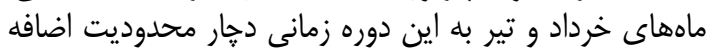

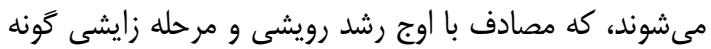
بلوط ايرانى مىباشد (9).

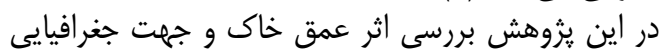

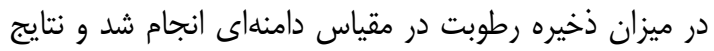

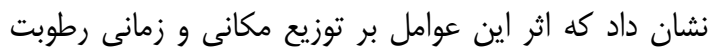

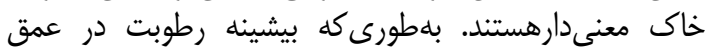

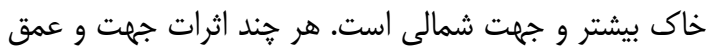

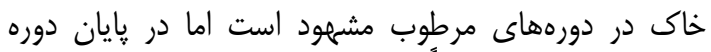

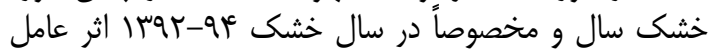

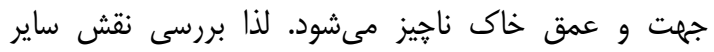
عوامل همانند ارتفاع از سطح دريا، ناجين شي، طول شيب، شكل 
1. Alizadeh, A. 2006. Soil, water and plant relationship Astane Ghodse Razavi Press, Mashhad. 484 pp (In Persian).

2. Afyuni, M.M., D.K. Cassel and W.P. Robarge. 1992. Effects of landscape position on soil water and corn silage yield. American Journal of Soil Science Society, 57(6): 1573-1580.

3. Da Silva, A.P., B.D. Kay and E. Perfect. 1994. Characterization of the least limiting water range of soils. American Journal of Soil Science Society, 58: 1775-1781.

4. Dyer, J.M. 2009. Assessing topography patterns in moisture use and stress using a water balance approach. Landscape Ecology, 24(3): 391-403.

5. Fralish, J.S. 1994. The effect of site environment on forest productivity in the Illinois Shawnee Hills. Ecological Applications, 4: 134-143.

6. Hayati, E., E. Abdi, M. Mohseni Saravi, B. Majnounian and G.B. Chirico. 2018. Time-varying soil water potential at different depths of soil under grassed and deciduous hill slopes. Forest and Wood Products, 70(4): 617-625 (In Persian).

7. Hossieni, A. and S.M. Hossieni. 2016. The role of topographic and edaphic factors in mortality of trees in middle Zagros Persian oak (Quercus brantii) forests. Journal of Zagros Forests Researches, 3(1) (In Persian).

8. Hosseinzadeh, J., A. Aazami, and M. Mohammadpour. 2015. Influence of topography on Brant`s oak decline in Meleh-Siah forest, Ilam Province. Iranian Journal of Forest and Poplar Research, 23(1): 190-197 (In Persian).

9. Tahmasebi,M., J. Hossienzadeh and A.R. Mir Badin. 2002. Phenology of Querques.sp and Pistacia.sp species in the forests of Ilam Province. Research Project of Agricultural and Natural Resources Research and Education Center, AREEO, Ilam, Iran, 33 pp (In Persian).

10. Jin, X.M., Y.K. Zang, M.E. Schaepman, G.W. Cleveres, Z.SU. Clrvers. 2008. Impact of elevation and aspect on the spatial distribution of vegetation in the Qilian mountain area with remote sensing data. The International Archives of the Photogrammetry. Remote Sensing and Spatial Information Sciences, Vol. XXXVII. Part B7. Beijing: 1385-1390.

11. Klute, A. 1986. Water retention: Laboratory method. In: A. Klute (Ed.), Methods of Soil Analysis. Part 1: Physical and mineralogical Methods. America Society of Agron-Soil Science Society of America, Madison, 9: 635-662.

12. Korner, C. and T. Jahr. 2005. Hydrological experiments around the superconducting gravimeter at moxa observatory. Journal of Geodynamic, 41(1-3): 268-275.

13. Mohammdpour, M., J. Hosseinzadeh, M.R. Jafari, A. Aazami, A. Najefifer. 2015. Project of recognition of ecological areas of the country: Plant Types of Ilam Province. Publisher: Institute of Forestry and Rangeland Research (In Persian).

14. Ortuno, M.F., Y. Garcia-Orellana, W. Conejero, M.C. Ruiz-Sanchez, O. Mounzer, J.J. Alarcon and A. Torrecillas. A. 2006. Relationships between climatic variables and sap flow, stem water potential and maximum daily trunk shrinkage in lemon trees. Plant and Soil, 279: 229-242.

15. Porporato, A. and I. Rodriguez. 2002. Ecoh hydrology a challenging multidisciplinary research perspective. Hydrological Science, 47(5): 811-821.

16. Sadeghi, S.H.R. and A. Vahideh. 2005. Change soil moisture in zone root in Atriplex Cansensciens. Journal of Rangeland, 1(2): 308-326 (In Persian).

17. Stephenson, N.L. 1990. Climatic control of vegetation distribution: The role of the water balance. American Naturalist, 135: 649-670.

18. Tromp-Van Meerveld, H.J. and J.J. McDonnell. 2006. On the interrelations between topography, soil depth, soil moisture, transpiration rates and species distribution at the hills slope scale. Advances in Water Resources, 29(2): 293-310.

19. Valinejad F., K. Ghorbani, M. Zakerinia, A.A. Dehghani and B. Ababaee. 2014. Performance assessment of SWAT model for estimating soil moisture. Master's Thesis Faculty of Soil and Water Engineering, Gorgan University of Agricultural Sciences and Natural Resources, 1(1): 85 pp (In Persian).

20. Venkatesh, B., N. Lakshman, B.K. Purandara and V.B. Reddy. 2010. Variability of soil hydrologic characteristics under different land covers a Case Study from Sahayadri Mountains, India: Proceedings of National Seminar on Sustainable Water Resource Management, Organised by NITKvers, Surathkal, India, 7-9 Jan.

21. Venkatesh, B., N. Lakshman, B.K. Purandara and V.B. Reddy. 2011. Analysis of observed soil moisture patterns under different land covers in Western Ghats,India. Journal of Hydrology, 397: 281294.

22. Whittaker, R.H. 1956. Vegetation of the Great Smoky Mountains Ecological Monographs, 26(1): 180.

23- Yang, J., H. Chen, Y. Nie, W. Zhang, K. Wang. 2016. Spatial variability of shallow soil moisture and its stable isotope values on a karst hillslope. Geoderma, 264: 61-67. 
$1 q$

24. Zarehaghi, D., M.R. Neyshabouri, M. Gorji, H. Monirifar and M. Shorafa. 2011. Determination of non-limiting water range for seedling growth of pistachio at two levels of soil compaction. Journal of Water and Soil Science, 22(3): 59-71 (In Persian).

25- Zhao, P., X.Y. Tang, P Zhao, C. Wang, J.L. Tang. 2013. Identifying the water source for subsurface flow with deuterium and oxygen-18 isotopes of soil water collected from tension lysimeters and cores. J. Hydrology, 503: 1-10.

26- Zhang, W., K.L. Wang, H.S. Chen, X.Y. He and J.G. Zhang. 2012. Ancillary information improves kriging on soil organic carbon data for a typical karst peak cluster depression landscape. Jornal of Science Food Agriculture, 92(5): 1094-1102. 


\title{
The Effect of Depth and Aspect on Soil Moisture in Dieback Affected Oak Forests (Case study: Meleh siah Forest, Ilam Province)
}

\author{
Ayad Aazami $^{1}$, Ahmad Hosseni ${ }^{2}$ and Jafar Hoseianzadeh ${ }^{3}$
}

1- Forests and Rangelands Research, Ilam Agricultural and Natural Resources Research and Education Center,

AREEO, Ilam, Iran, (Corresponding author: ayadaazami@ yahoo.com)
2- Forests and Rangelands Research, Ilam Agricultural and Natural Resources Research and Education Center, AREEO, Ilam, Iran

3- Forests and Rangelands Research, Ilam Agricultural and Natural Resources Research and Education Center, AREEO, Ilam, Iran

Received: June 10, 2018

Accepted: July 22, 2018

\begin{abstract}
Recognition of humidity changes is important because of its relevance to hydrological, ecological and physiographic characteristics of the area. Therefore, soil moisture content in four main directions and three depths of 50,70 and $110 \mathrm{~cm}$ of soil for two years from March 2013 to September 2012 in the forest area of Meleh-Siah Ilam was measured and analyzed in a randomized complete block design with soft SAS was implemented. The results showed that soil moisture and soil depth and direction were affected by moisture storage in the south and north directions with 21.9 and 19.7 and in the eastern and western slopes 19 and $15.5 \mathrm{~mm}$. Also, the average monthly moisture content in the three depths of 70,110 and 50 was 18.4, 17.4 and $7.5 \mathrm{~mm}$ respectively. The average monthly soil moisture storage at three depths50, 70 and 110 are 18.4, 17.4 and $7.5 \mathrm{~mm}$, respectively. In other words, the effect of soil depth and geographic orientation on the soil moisture is effective but not noticeable in dry years and in dry months. Also, the results showed that the monthly dryness rate (from wet to dry period) in the wet year is more than dry year and increases with increasing depth of soil. Based on soil texture analysis, the optimum moisture content for plant growth was between $15 \%$ and $30 \%$, and based on this, the maximum drought stress on vegetation and especially oak species was in August and September, which coincided with the peak of vegetative growth And the reproductive stage of the oak tree species.
\end{abstract}

Keywords: Oak forests, Aspect, Depth soil, Dieback, Soil moisture 